O INDETERMINADO CRAVADO DO TEMPO: UMA PERFORMANCE DA SENSAÇÃO PERANTE O OFÍCIO-PESQUISA NO REVELAR DAS FOLHAS

THE INDETERMINATE SPIKED OF TIME: A PERFORMANCE OF SENSATION BEFORE THE CRAFT-RESEARCH IN THE REVEALING OF LEAVES

Natalia Negretti

Como citar este texto:

NEGRETTI, Natalia. O indeterminado cravado do tempo: Uma performance da sensação perante o ofício-pesquisa no revelar das folhas. Cadernos do Lepaarq, v. XVII, n.33., p. 212-222, Jan-Jun. 2020. 


\title{
O indeterminado cravado do tempo: Uma performance da sensação perante o ofício- pesquisa no revelar das folhas
}

\author{
Natalia Negretti ${ }^{\mathrm{a}}$
}

Resumo: Este ensaio discorre acerca da relação entre pesquisa etnográfica e emoções a partir de um compilado de práticas que envolveram uso de imagens em campo, de registros fotográficos de interlocutores e um fazer afetivo em torno de tais lembranças aplicado à técnica da fitotipia. Neste sentido, o trabalho localiza o entroncamento de afeto e pesquisa, corroborando os estudos sobre etnografia, antropologia e imagem como espaço contínuo e estendido à esfera-ofício da pesquisa e circulação..

\section{Palavras Chave:}

Etnografia, Emoções, Fotografia, Fitotipia, Mobilidades

\begin{abstract}
This essay discusses the relationship between ethnographic research and emotions from a compilation of practices that involved the use of field images, photographic records of interlocutors and an affective make around such memories applied to the technique of phytotyping. In this sense, the work locates the connection of affection and research, corroborating the studies on ethnography, anthropology and image as a continuous space and extended to the sphere of trade of research and circulation.
\end{abstract}

\section{Keywords:}

Ethnography, Emotions, Photography, Phytotyping, Mobilities

\footnotetext{
${ }^{a}$ Doutoranda em Ciências Sociais pelo Programa de Pós-Graduação em Ciências Sociais da Universidade Estadual de Campinas (PPGCSUnicamp), Brasil. Agência financiadora: Coordenação de Aperfeiçoamento de Pessoal de Nível Superior (CAPES), Brasil. E-mail: natalia_negretti@yahoo.com.br
} 


\section{INTRODUÇÃO}

A fitotipia tem sido apresentada pela arte como uma técnica, com ênfase do termo "alternativa", de impressão ou reprodução de imagens pela luz solar. Oriunda, na narrativa, do século XIX, o eco interessante da fitotipia é o paradoxo que produz quando manuseada. A luz que colabora com a reprodução da imagem se torna a imagem já reproduzida, motivo de evitação, convertendose numa possibilidade de atentar à noção de conservação. A ideia de fotografia como "arquivo do tempo" nos leva às reflexões de Etienne Samain, para quem a imagem "é o lugar de um processo vivo, ela participa de um sistema de pensamento" (SAMAIN, 2012, p. 158). Nesse sentido, entre o jogo de luzes até o saber em listas de folhas mais adequadas, o fazer fitotipia pode revelar também relações entre tempo, indeterminações e buscas.

Como maneira de parafrasear o ofício de pesquisar, atribuo a este ensaio um exercício de me debruçar ao lugar-chave (FRANÇA, 2010) da emoção em uma pesquisa em andamento. Contextualizada por esta, a fitotipia realizada se desencadeou através de fluxos (INGOLD, 2012) no que refere etnografia, interlocução e emoção. Contemplada a priori por idas e vindas a um equipamento público, que chamo de Guarida Lia, para mulheres e homens, considerados - sob a perspectiva etária e de direitos - idosos em situação de rua no centro de São Paulo, e levantamentos de trajetórias de vida, a etnografia, com o tempo passou a ser tecida por acompanhamentos e trânsitos com alguns interlocutores. O tempo, primordial para tais passamentos, também foi enfático ao que concerne aos registros fotográficos. Em grande parte das interlocuções, que para além de diversificadas, eram também dinamizadas por ocasiões, entre outras, a sós ou na instituição, por exemplo, as fotografias passavam ao serem tiradas. Junto com o campo, o fotografar contou também com o correr do tempo. A relação com as fotografias na etnografia foi um marcador de passagem de tempo nas relações advindas pela pesquisa e às distintas interlocuções tecidas. Ao contemplar a etnografia, a relação com as fotografias se tornou também uma ponte de sensações e sentimentos.

Neste fluxo, a fitotipia arranjou processos da pesquisadora em lidar com aS emoções. 0 procurar aprender a "fitotipiar" requereu trabalhar, de outros modos que não a escrita, costurando tais relações e dando performance imagética à uma dimensão - de lembranças - desprovida de intencionalidade; ao que não estava para o narrável; ao tempo de não análise (FAVRET-SAADA, 2005).

Olhar para a fitotipia realizada é uma oportunidade de compreensão frente às temporalidades dos fluxos na pesquisa. Se o ato de fitotipiar é compreendido como recurso performático de um fluxo, relembrar seu processo leva a um campo e período de "expressar o fato de justamente não ter palavras"(DIDI-HUBERMAN, 2016, p. 52), bem como ao fluxo em que "a memória abre do presente para o passado e deste para o presente"(BOSI, 2003, p. 45). Desta maneira, atentar tal processo confere à ocasião de fazer fitotipia uma alternativa de subjetividade às sensações em determinado período de campo e relações. Como atenta Maria Claudia Coelho e 
Claudia Rezende (2010), "se a lembrança das respostas emotivas está sempre associada ao contexto de interação que as produziu, já temos o fato de que o sentimento não é sentido de forma abstrata nem independente de interações sociais específicas" (REZENDE, COELHO, 2010, n.p).

Por essa vista, o processo em torno da fitotipia se insere ao enquadramento de gramáticas dos sentimentos (REZENDE, COELHO, 2010). Destarte, através de tal tempo corrido, localiza o entroncamento de afeto e pesquisa, corroborando os estudos sobre etnografia, antropologia e imagem como espaço contínuo e estendido à esfera-ofício da pesquisa e circulação.

Pela sequencia e relação das folhas - papel fotográfico; transparência; folha vegetal - na reprodução de imagens, se debruçar na fitotipia articulou também as folhas escritas e as em branco que contemplavam a pesquisa.

Enquanto as três primeiras imagens dessa representação fotográfica (KOSSOY, 1989) mostram as folhas inteiras, as três últimas visam atentar os ângulos que alinhavam cena, personagens e planta, através do meu olhar narrador, ao registro (fotografia) seguida de reprodução em folha vegetal ("produção fitotípica") e novamente fotografada (imagens do ensaio).

Aciono deste modo a noção de performance pelo que Renato Cohen (2002) conjuga "se fazer representar" (COHEN, 2002, p. 40). O conjunto trazido para este ensaio então se refere ao entendimento de "performance como uma função do espaço e do tempo" (COHEN, 2002, p.28). É neste interim que a fitotipia movimentou a etnografia. No sentido em que "qualquer descrição de performance fica muito mais distante da sensação de assisti-las" (COHEN, 2002, p.30) as imagens trazidas ao ensaio são os registros de um processo minimamente em tríade: etnográfico, emotivo e fitotípico. Trabalhar pela fotografia foi uma maneira de atentar para esquecimento, emoção e lembrança como vias de fatos. 


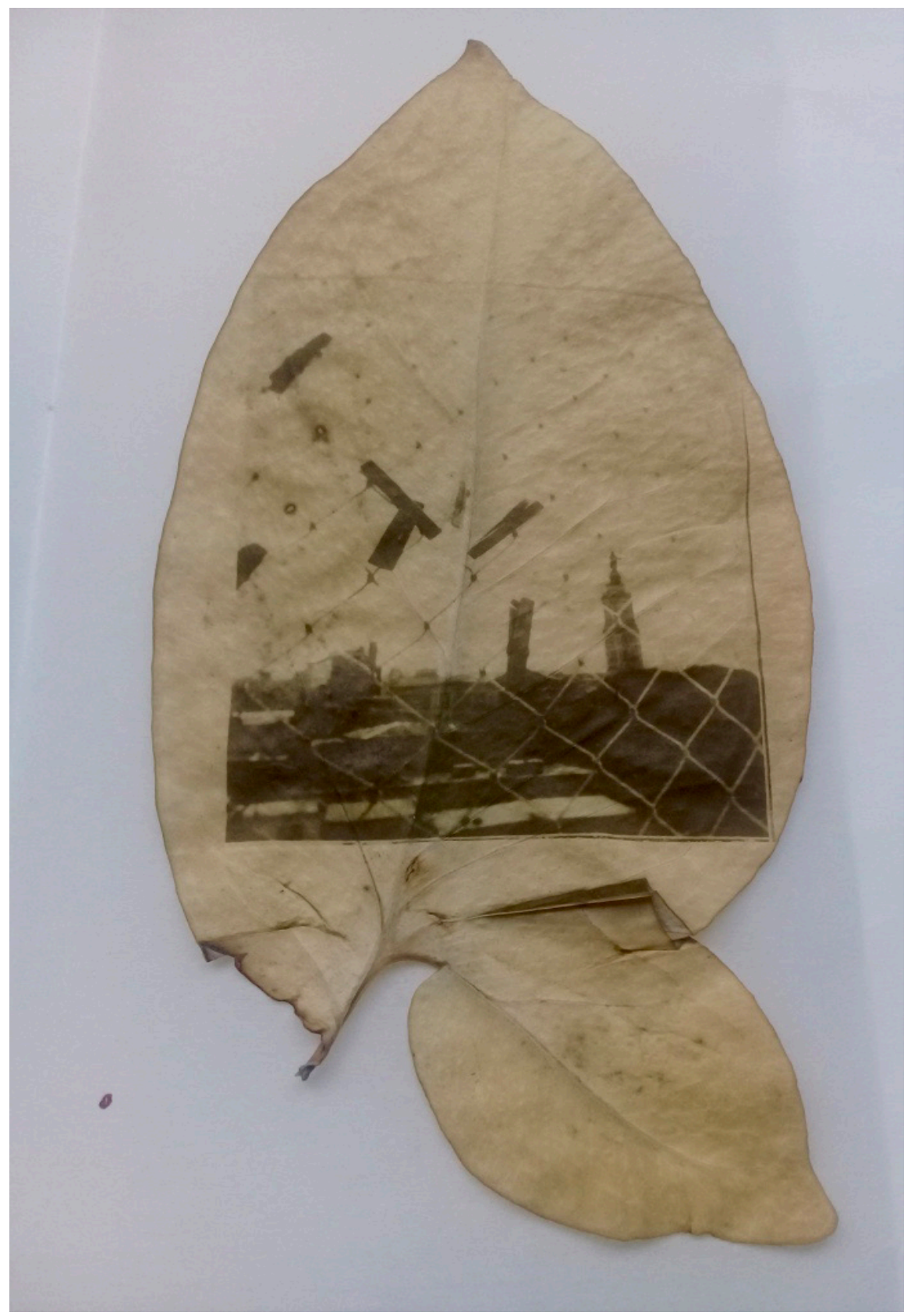

Figura 1 - Uma Janela da Guarida Lia 


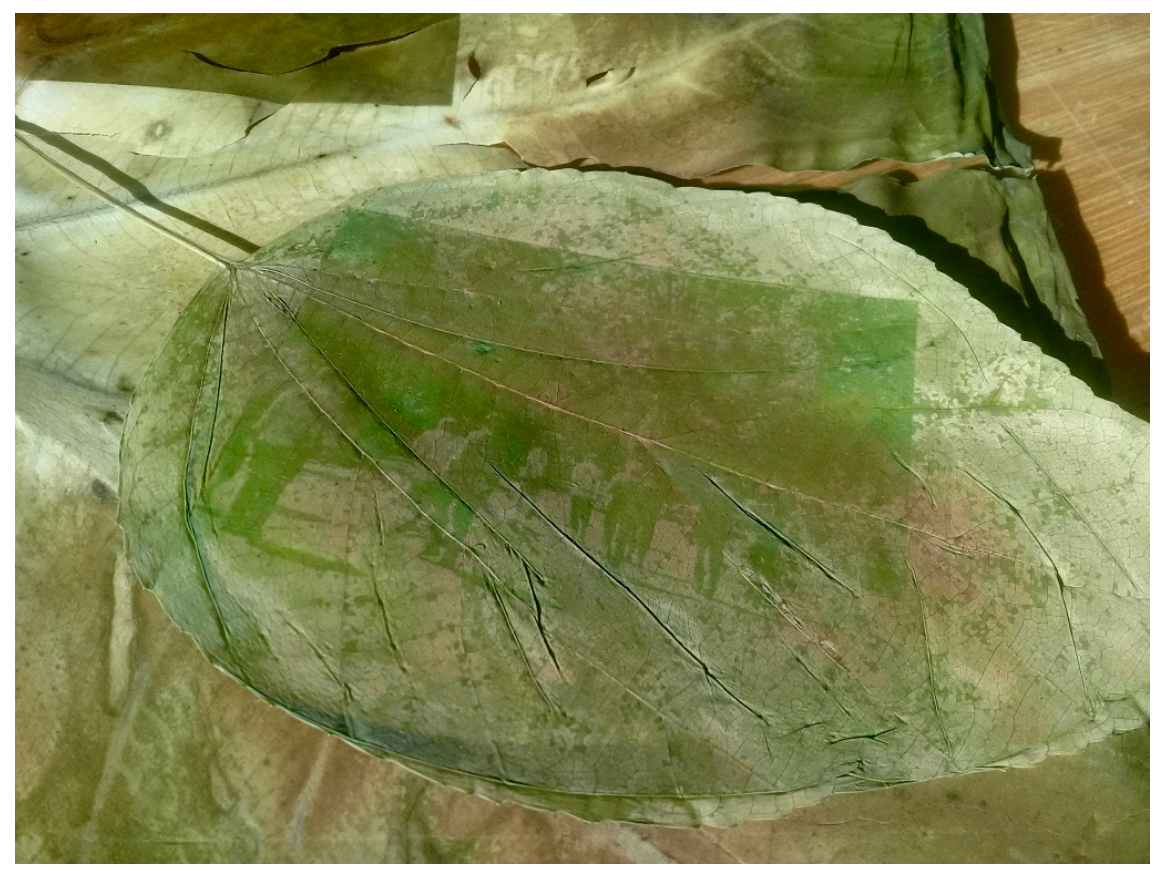

Figura 2 - Caminhantes em folha de amora



Figura 3 - Íris em Tabóia, vidro e folha em branco 


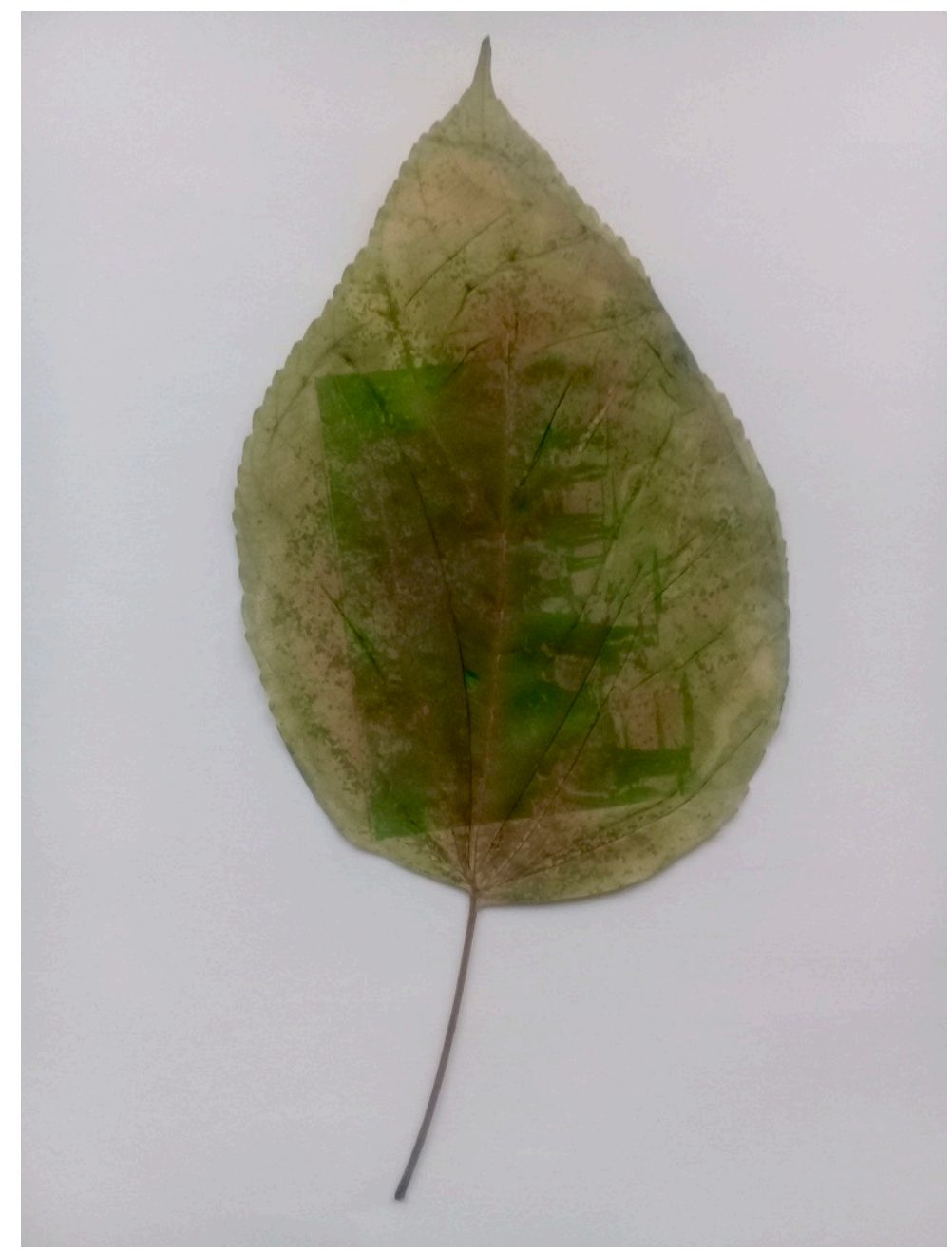

Figura 4 - Folha de Amora em folha em branco

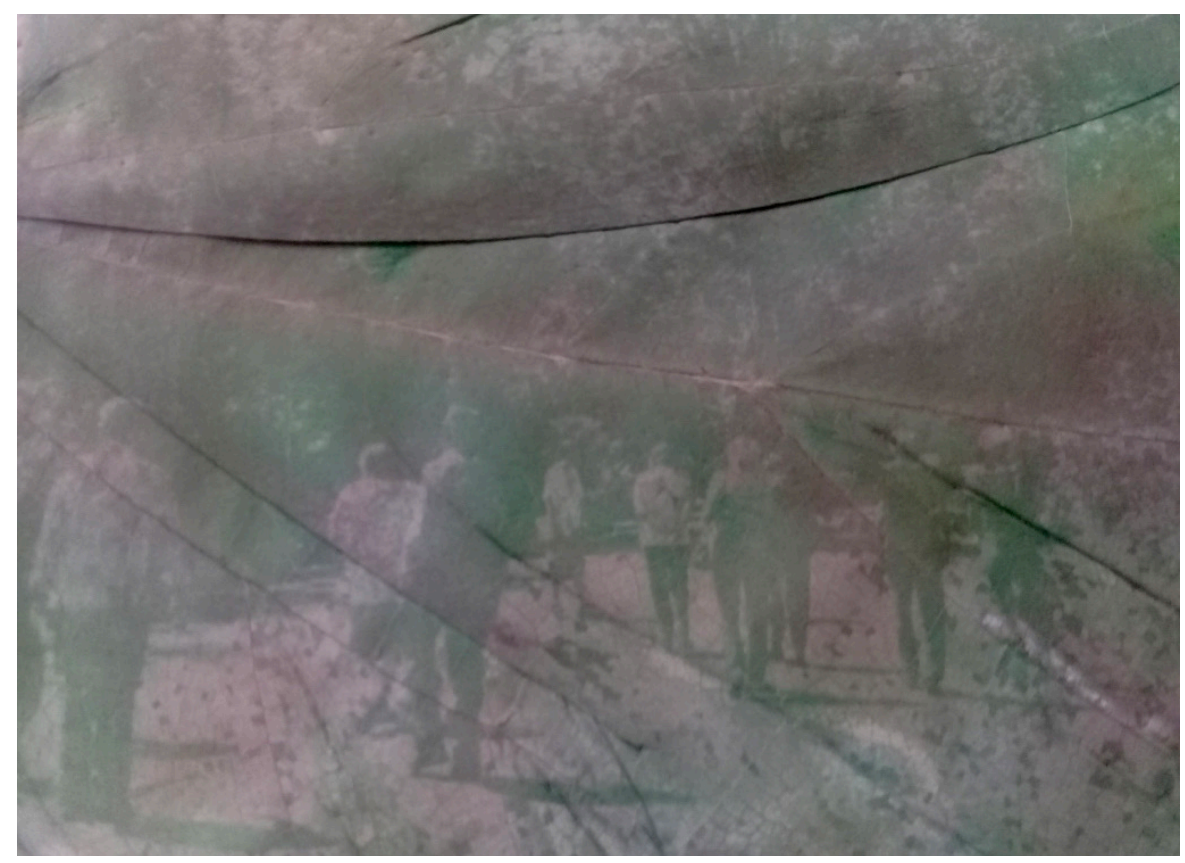

Figura 5 - Porosidade em circuito do Lepaarq, v. XVII, n.33., p. 212-222, Jan-Jun. 2020. 


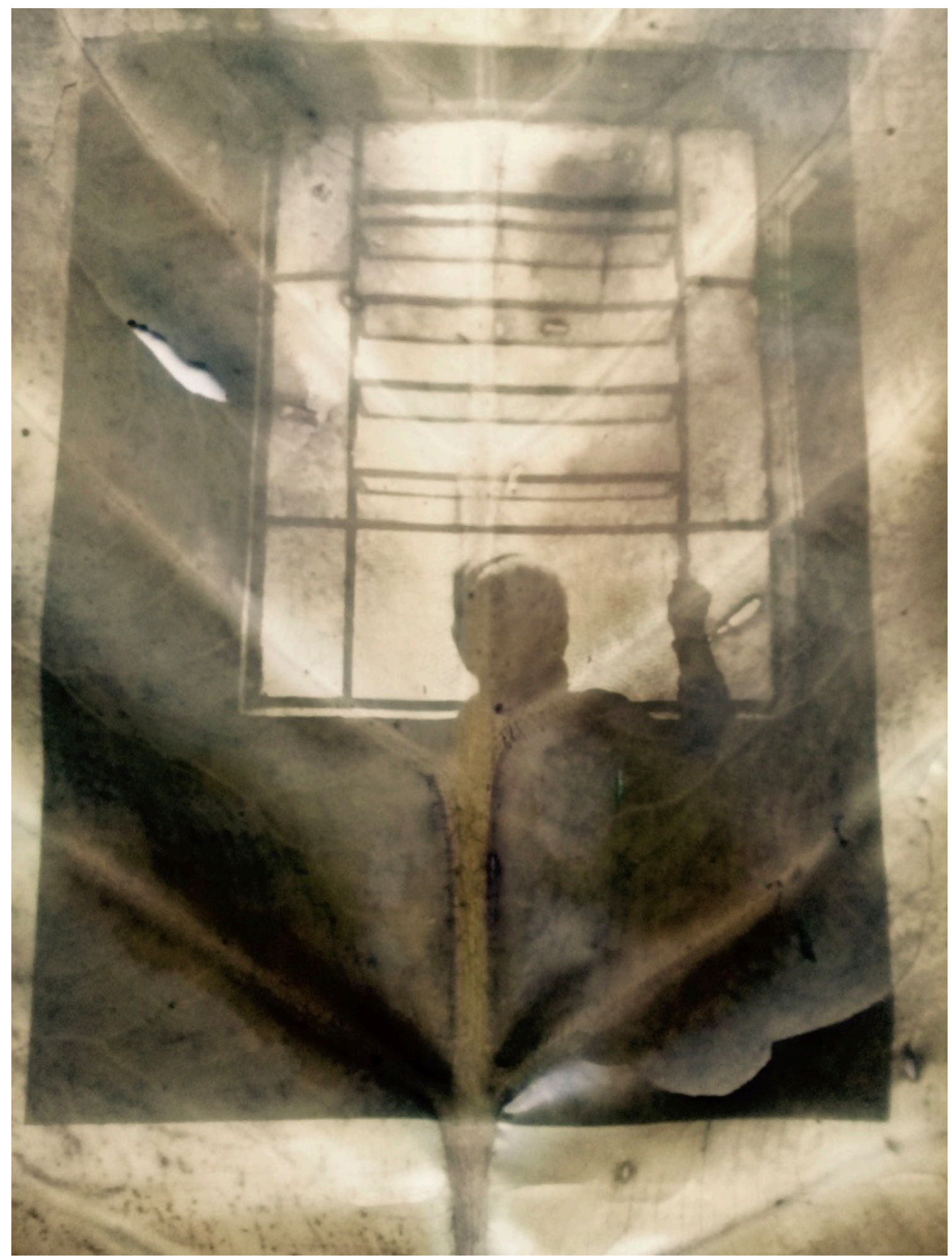

Figura 6 - Segurar o olhar 


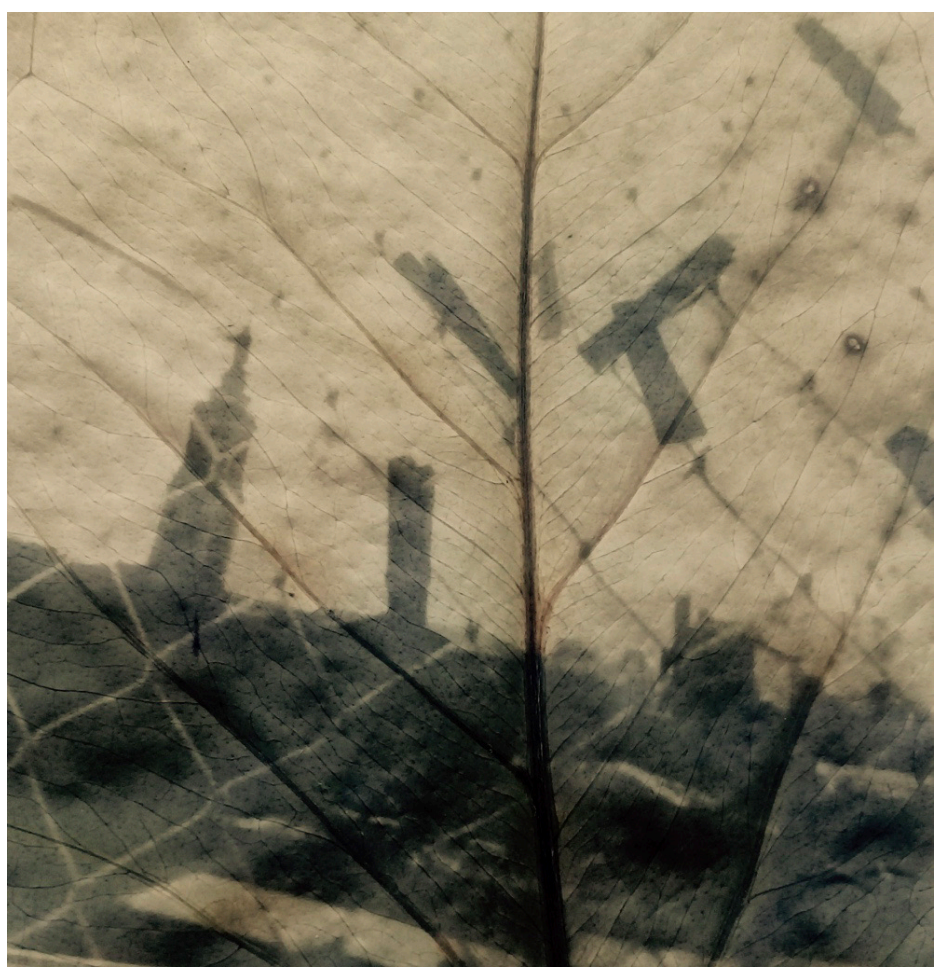

Figura 7 - Perto e outro lado

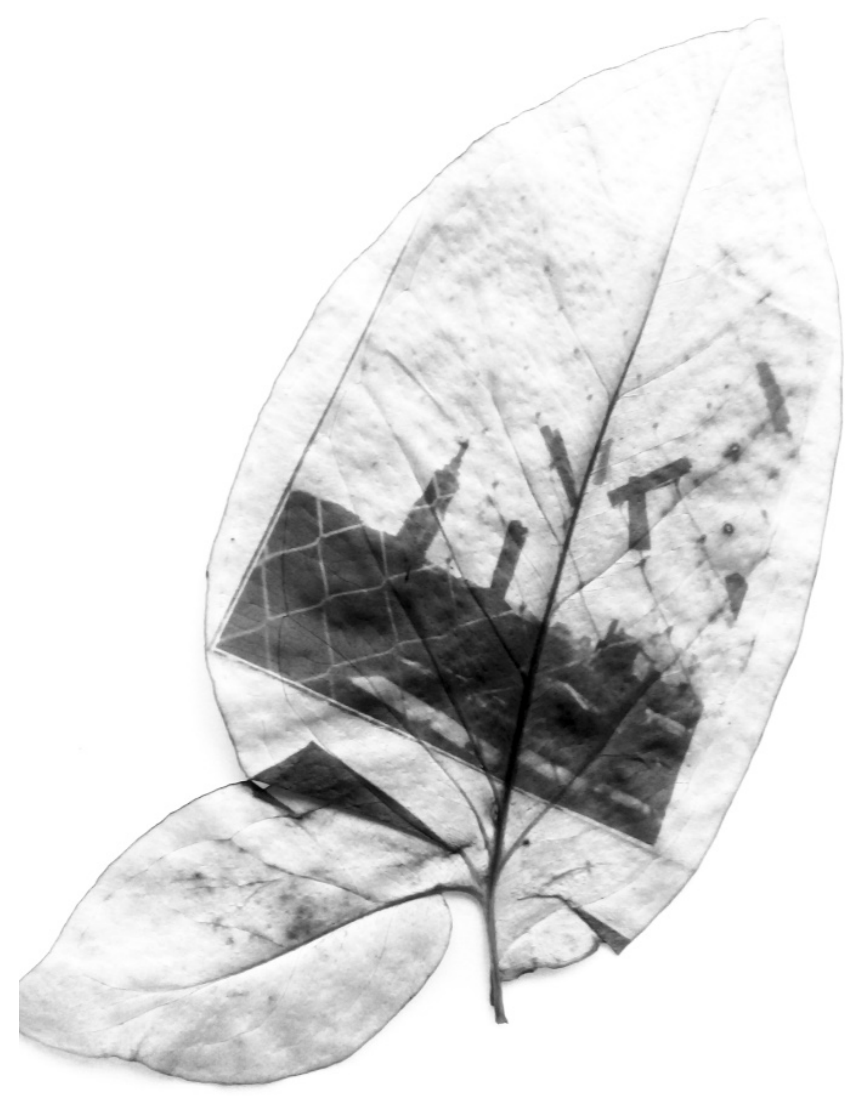

Figura 8 - Folha com folha 
O "fitotipiar" rearranjou as lembranças iniciadas com o método etnográfico e a valorização de outros processos. Mirar lembranças "fitotipiadas" é reconhecer a presença de subjetividades e do sensível no ofício-pesquisa. Como "uma malha de linhas entrelaçadas de crescimento e movimento" (INGOLD, 2012, p. 27), a fitotipia não cessou as temporalidades atribuídas aos seus fluxos.

Os efeitos da interação no tempo, nas emoções e do tempo da interação são presentes, portanto, no conjunto proposto. Este contempla um lugar possível para narrar por imagens, considerando as sobreposições temporais, flashes fugazes (SILVEIRA, 2007) que também se transformaram e se transformarão.

A performance se deu, deste modo, no arcabouço da fitotipia; em seu produto e modo. Se a memória foi produzida por ela, a emoção pôde ser trabalhada através da mesma. Destarte, se num momento clarão, o empreendimento literal foi entregar as imagens em folhas vegetais à esteira do tempo, hoje, na evitação de luz e por tempo incerto é que tal impressão se sustenta. A certeza é a transformação dos carimbos. Neste desenfado, as caixas técnicas para a conservação indeterminada do produto da fitotipia se caracterizam como temporárias. É sob o indeterminado cravado no tempo, entretanto, que estão as emoções de rever uma janela da Guarida Lia, alguns de seus moradores fora dela e Íris. Três personagens em cena e de um fluxo de interlocução no outro lado das folhas. 


\section{REFERÊNCIAS}

BOSI, Ecléa. O tempo vivo da memória: ensaios de psicologia social. São Paulo: Ateliê Editorial, 2003.

REZENDE, Claudia Barcellos e COELHO, Maria Cláudia. Antropologia das Emoções. Rio de Janeiro: Editora Fundação Getúlio Vargas. Edição do Kindle.

COHEN, Renato. Performance como linguagem. Criação de um tempo-espaço de experimentação. Editora Perspectiva. São Paulo, 2002.

DIDI-HUBERMAN, Georges. Que Emoção? Que Emoção! Tradução de Cecília Ciscato. São Paulo: Editora 34, 2016. 72 p.

FRANÇA, Isadora. Consumindo lugares, consumindo nos lugares: homossexualidade, consumo e subjetividades na cidade de São Paulo. Tese de doutorado. Programa de Ciências Sociais. Universidade Estadual de Campinas, 2010.

FAVRET-SAADA, Jeanne. Ser afetado. São Paulo: Cadernos de Campo № 13, 2005 [1990].

INGOLD, Tim. Trazendo as coisas de volta à vida: emaranhados criativos num mundo de materiais. Horiz. antropol., Porto Alegre, v. 18, n. 37, p. 25-44, June 2012.

KOSSOY, Boris. Fotografia e História. São Paulo, Ática, 1989.

SAMAIN, Etienne. As peles da fotografia: fenômeno, memória/arquivo, desejo - DOI 10.5216/vis. v10i1.23089. Visualidades, 10(1). 2013.

SILVEIRA, Flávio Leonel Abreu da. A poética do cotidiano missioneiro: etnografia e reflexão sobre si mesmo. Compartilhando imagens e emoções com os contadores de causos nas Missões Gaúchas. Cadernos de Campo (USP), v. 16, p. 13-29, 2007. 